\title{
Epididymal anomalies in boys with undescended testis or hydrocele: Significance of testicular location
}

\author{
Sun-Ouck Kim*, Seong Woong Na, Ho Song Yu and Dongdeuk Kwon
}

\begin{abstract}
Background: Epididymal anomalies and patent processus vaginalis are frequently found in boys with cryptorchidism or hydrocele. We conducted this study to evaluate the association between epididymal anomalies and testicular location or patent processus vaginalis in boys with undescended testis or hydrocele.

Methods: Children undergoing surgery with undescended testis (group A, 136 boys and 162 testes) or communicating hydrocele (group B, 93 boys and 96 testes) were included. Testicular locations and epididymal anomalies were investigated prospectively. An anomalous epididymis was defined as anomalies of epididymal fusion that consisted of loss of continuity between the testis, the epididymis, and the long looping epididymis. The epididymis was considered normal when a normal, firm attachment between the testis, the caput, and the cauda epididymis was present.

Results: The mean ages of groups A and B were $24.6 \pm 19.7$ (range, 8-52 months) and $31.4 \pm 20.6$ months (range, 10-59 months). The incidence of epididymal anomalies was significantly higher in group A than that in group B ( $65.4 \%$ vs. $13.5 \%, P<0.001)$. The incidence of epididymal anomalies in boys with undescended testis was significantly different according to testis location. Epididymal anomalies were observed in $100 \%, 91.4 \%$, and $39.3 \%$ of cases when the testis was located in the abdomen, inguinal canal, and distal to the external inguinal ring, respectively $(P<0.001)$.

Conclusion: We conclude that epididymal anomalies were more frequent in boys with undescended testis than in boys with hydrocele, and that these anomalies were more frequent when undescended testis was at a higher level. These results suggest that testicular location is associated with epididymal anomalies rather than patent processus vaginalis.
\end{abstract}

Keywords: Undescended testis, Epididymis, Hydrocele

\section{Background}

Epididymal and vasal anomalies are associated with undescended testis. These anomalies occur in association with undescended testis at varying degrees of 32-79\% according to various epididymal anomaly diagnostic criteria [1-7]. These anomalies can be found either during orchiopexy or hydrocelectomy/hernia repair. The patency of processus vaginalis is also strongly related with epididymal anomalies [8].

\footnotetext{
* Correspondence: seinsena@hanmail.net

From the Department of Urology, Chonnam National University Medical School, Gwangju, South Korea
}

The surgeon must be aware of associated epididymal anomalies when operating to correct undescended testes or hydrocele and not to dissect an elongated epididymis, a cranially located testis with a descended long or dissociated epididymis, or a cranially located testis [5]. Although epididymal anomalies in children with undescended testis or hydrocele are detected frequently during the surgery, only limited and sporadic reports are available on this subject.

Some reports have suggested that epididymal anomalies associated with more cranially located testis are more severe than those associated with more caudally located testis among boys with undescended testis [4]. However, 
no study has evaluated epididymal anomalies based on the location of undescended testis, which represents the exact incidence rate. We prospectively evaluated the relationship between epididymal anomalies in boys with undescended testis or hydrocele. The aim of this study was to clarify whether patent processus vaginalis or undescended testis is a more important factor in epididymal anomalies. We specially focused on the severity of epididymal anomalies according to testicular location in boys with undescended testis to better understand the relationship between epididymal morphology and testicular descent.

\section{Methods}

\section{Patients and study design}

We included children undergoing an inguinal exploration for undescended testis or a communicating hydrocele in the urologic department of our hospital between January 2011 and July 2013. A communicating hydrocele was defined by the size change history and a sac extending to the groin on ultrasound sonography. We performed a crosssectional study to determine the incidence of epididymal anomalies in these children. Boys with any of the following were excluded from the study: associated disorders, such as hypospadias, exstrophy, imperforated anus, sex development disorders, ectopic testes, or vanishing testis. The spermatic cord was isolated after incising the cremasteric fascia, and the hernia sac was high-ligated when present. Orchiopexy was performed by placing the testis into the subdartos pouch. Hydrocelectomy was performed using a typical inguinal approach, and the testis was delivered to the groin so the epididymal anomaly could be examined. Written informed consent for data collection and participation in the study was obtained from a parent or guardian. This study received approval from the local ethics committee (CNUH institutional review board). The study procedures complied with the guidelines provided by the Declaration of Helsinki.

\section{Definition of epididymal anomalies}

Testicular locations and epididymal anomalies were investigated carefully. According to morphological classification by Barthold and Redman [9], an anomalous epididymis was defined as an anomaly of epididymal fusion consisting of loss of continuity between the testis and the epididymis or long looping epididymis. The epididymis was considered normal when a normal firm attachment between the testis and the caput and cauda epididymis was present.

\section{Statistical analyses}

SPSS ver. 17 for Windows software (SPSS Inc., Chicago, IL, USA) was used for statistical analyses. Data were analyzed with the chi-square test. $P$-values $<0.05$ were deemed significant.

\section{Results}

A total of 229 boys (258 testes) with undescended testis (group A: 136 boys and 162 testes) or with hydrocele (group B: 93 boys and 96 testes) were included in this study. The mean ages in groups A and B were $24.6 \pm$ 19.7 (range, 8-52 months) and $31.4 \pm 20.6$ months (range, 10-59 months), respectively. In total, 110 patients (left: 52, right: 58) in group A had unilateral lesions and 26 patients had bilateral lesions. A total of 90 boys in group B had unilateral lesions (left: 55 , right: 35 ) and three had bilateral lesions. The patient demographic data are shown in Table 1.

The incidence of epididymal anomalies was significantly higher in group A than that in B $(65.4 \%$ [106/162] vs. $13.5 \%$ [13/96], $P<0.001$ ) (Table 2). The incidence of epididymal anomalies in group $\mathrm{A}$ was $100 \%(20 / 20)$ when the affected testis was found in the abdomen, 91.4 \% (53/58) when it was found in the inguinal canal and $39.3 \%(33 / 84)$ when it was found in the distal to external inguinal ring. This result indicates that higher testicular locations were associated with higher frequencies of epididymal anomalies $(P<0.001)$ (Table 3$)$.

\section{Discussion}

We evaluated the associations between epididymal anomalies and testicular location or patent processus vaginalis in boys with undescended testis or hydrocele, specially focusing on severity of the epididymal anomalies according to testicular location in boys with undescended testis. The incidence of epididymal anomalies was significantly higher in boys with undescended testis (65.4\%) than in boys with hydrocele (13.5\%).

The estimated overall incidence of epididymal anomalies in boys with undescended testis and hydrocele was $46.1 \%$, suggesting that testicular location contribute more to epididymal anomalies than patent processus vaginalis. Epididymal anomalies were found more frequently in boys with a higher testicular location. All boys

Table 1 Patient characteristics

\begin{tabular}{lll}
\hline & Group A & Group B \\
\hline Mean age (months) & $24.6 \pm 19.7$ & $31.4 \pm 20.6$ \\
No. of boys ( $\mathrm{n})$ & 136 & 93 \\
No. of testis ( $\mathrm{n})$ & 162 & 96 \\
Bilaterality (n) & & \\
Lt. & 52 & 55 \\
Rt. & 58 & 35 \\
Bilateral & 26 & 3 \\
\hline
\end{tabular}

No. $=$ number, $\mathrm{Lt}=$ left, $\mathrm{Rt}=$ right, Group A: undescended testis, Group B: hydrocele 
Table 2 Type of epididymis in cases of undescended testis and hydrocele

\begin{tabular}{lll}
\hline Type of epididymis & \multicolumn{2}{l}{ No. of boys (\%) } \\
\cline { 2 - 3 } & Group A & Group B \\
\hline Normal epididymis & $56(34.6)$ & $83(86.5)$ \\
Normal firm attachment & $32(19.8)$ & $45(46.9)$ \\
Widening of the mesentery & $24(14.8)$ & $38(39.6)$ \\
Abnormal epididymis $^{\mathrm{a}}$ & $106(65.4)$ & $13(13.5)$ \\
Complete separation of the caput $_{\text {Complete separation of the cauda }}$ & $27(16.7)$ & $0(0)$ \\
Complete separation of the caput and cauda & $20(12.3)$ & $6(6.3)$ \\
Long looping type & $27(16.7)$ & $0(0)$ \\
\hline
\end{tabular}

No. $=$ number, Group A: undescended testis, Group B: hydrocele. ${ }^{a}$ Fisher's exact test, $P=0.001$

with undescended testis located in intra-abdominal area had epididymal anomalies, $91.4 \%$ when the undescended testis was in the inguinal canal, and $39.3 \%$ when it was distal to external inguinal ring.

Controversies exist regarding the role of the epididymis in testicular descent, as epididymal anomalies have been found in 36-79 \% of boys with undescended testis. Most studies that have reported anatomical abnormalities of epididymis in boys with undescended testis have been sporadic and used different methods, and no recent data were found [1-7]. Mollaeian et al. reported that epididymal and vas anomalies occur with an overall frequency of $36 \%$ in boys with undescended testis [7]. Gill et al. reported that epididymal anomalies were detected in $43 \%$ of boys with undescended and vanishing testis [4]. In the present study $65.4 \%$ of boys with undescended testis had epididymal anomalies. The reason for the discrepancy may be due to different evaluation tools used in the studies. We used the most recently reported and most widely used epididymal anomaly classification [9].

Factors that have been suggested as important for normal testicular descent include normal gubernaculum, epididymis, and intra-abdominal pressure, and innervation by the genitofemoral nerve of the gubernaculums $[10,11]$. However, some boys with normally descended testis have epididymal and vassal anomalies [12]. Elder evaluated the incidence of epididymal anomalies based

Table 3 Epididymal anomalies according to location of undescended testis

\begin{tabular}{lll}
\hline Location of testis & $\begin{array}{l}\text { Epididymal anomalies } \\
\text { No. of testis (\%) }\end{array}$ & $P$-value \\
\hline Intra-abdominal & $20 / 20(100)$ & \\
Inguinal canal & $53 / 58(91.4)$ & $<0.001^{*}$ \\
Distal to external inguinal ring & $33 / 84(39.3)$ & \\
Total & $106 / 162(65.4)$ & \\
\hline
\end{tabular}

No number; *Fisher's exact test on patency of the processus vaginalis in patients with hernia, hydrocele, and undescended testis and suggested that most epididymal abnormalities probably do not contribute to the testicular descent process [6]. That author insisted that an abnormal epididymis with undescended testis maybe an associated finding and not a cause, as he reported that $64 \%$ of cases showed an epididymal anomaly when the processus vaginalis was completely patent, whereas $11 \%$ were abnormal when the processus vaginalis was incompletely patent [6]. We found a rather low incidence of boys with patent processus vaginalis compared to that in Elder's study. We found that $13.3 \%$ of boys with a communicating hydrocele and completely patent processus vaginalis and normally descended testis had epididymal anomalies. This discrepancy may be due to different inclusion criteria for the studies. We compared the incidence of epididymal anomalies between boys with normal descended testis with patent processus vaginalis/hydrocele and boys with undescended testis.

Knowledge of normal testicular anatomy is necessary to understand epididymal anomalies. The normal epididymis curves along the testis but the epididymal body may be slightly detached from the testis body. The epididymal head remains in close proximity with the cranial pole of the testis, while the cauda epididymis disappears within the gubernaculum [13]. The testis and caput epididymis arise from the genital ridge, whereas the body of the epididymis and vassal structure arise from the mesonephric tubules and Wolffian duct. Then, union of the rete testis and mesonephric tubules begins at 12 weeks of gestation. During involution of the mesonephric duct, the testis receives blood from the internal spermatic artery, and the vessel structures derive blood supply from the internal iliac artery. Ductal or epididymal atresia or segmental anomalies may occur die to a vascular accident related to this difference in vascular supply [14].

Epididymal anomalies are associated with maldescent of the testis and may account for impaired future fertility $[3,4]$. A clinically important point to consider is possible infertility due to epididymal or vassal malformation of the sperm transporting mechanism. Infertility problems in patients with undescended testis may partly result from obstruction associated with an abnormal epididymis $[3,4]$. Koff and Scaletscky reported that an elongated epididymis may present problems for sperm maturation and transportation, and may be associated with severe impairment in future fertility, despite early surgical correction of undescended testis [5].

In the present study, epididymal anomalies were detected in all boys when the affected testis was found in the intra-abdominal area, whereas $91.4 \%$ showed an abnormal condition when the testis was in the inguinal canal and $39.3 \%$ when it was found distal to the external 
inguinal ring. More severe epididymal anomalies and vassal anomalies are encountered in boys with testis located in the intra-abdominal or high inguinal position in a small case series $[1,4]$. Our results suggest that higher testicular locations were associated with more frequent epididymal anomalies, as shown previously. It appears that future fertility issue should be considered when epididymal anomalies are detected at orchiopexy, particularly when the affected testis is located in a high cranial position.

\section{Conclusions}

We conclude that epididymal anomalies were more frequent in boys with undescended testis than in boys with hydrocele, and that these anomalies were more frequent when the undescended testis was at a higher level. This result suggests that testicular location, rather than patent processus vaginalis, is associated with epididymal anomalies.

\section{Competing interests}

The authors declare no competing interests.

\section{Authors' information}

Sun-Ouck Kim, Seong Woong Na, Ho Song Yu, and Dongdeuk Kwon Department of Urology, Chonnam National University Medical School, Gwangju, Korea.

\section{Authors' contributions}

SOK help conceive and design the study and drafted the manuscript. SWN collected the data and performed the statistical analyses. HSY assisted with conception and design of the study. DDK conceived and supervised the study and helped draft the manuscript. All authors have read and approved the final version of the manuscript.

Received: 8 May 2015 Accepted: 12 October 2015

Published online: 24 October 2015

\section{References}

1. Marshall FF, Shermeta DW. Epididymal abnormalities associated with undescended testis. J Urol. 1979;121(3):341-3.

2. Mininberg DT, Schlossberg S. The role of the epididymis in testicular descent. J Urol. 1983;129(6):1207-8.

3. Heath AL, Man DW, Eckstein HB. Epididymal abnormalities associated with maldescent of the testis. J Ped Surg. 1984;19(1):47-9.

4. Gill B, Kogan S, Starr S, Reda E, Levitt S. Significance of epididymal and ductal anomalies associated with testicular maldescent. J Urol. 1989;142(2 Pt 2):556-8.

5. Koff WJ, Scaletscky R. Malformations of the epididymis in undescended testis. J Urol. 1990;143(2):340-3.

6. Elder JS. Epididymal anomalies associated with hydrocele/hernia and cryptorchidism: implications regarding testicular descent. J Urol. 1992;148(2 Pt 2):624-6.

7. Mollaeian M, Mehrabi V, Elahi B. Significance of epididymal and ductal anomalies associated with undescended testis: study in 652 cases. Urology. 1994:43(6):857-60.

8. Han CH, Kang SH. Epididymal anomalies associated with patent processus vaginalis in hydrocele and cryptorchidism. J Korean Med Sci. 2002;17(5):660-2.

9. Barthold JS, Redman JF. Association of epididymal anomalies with patent processus vaginalis in hernia, hydrocele and cryptorchidism. J Urol. 1996:156(6):2054-6.

10. Elder JS, Isaacs JT, Walsh PC. Androgenic sensitivity of the gubernaculums testis: evidence for hormonal/mechanical interaction in testicular descent. J Urol. 1982;127(1):170-6
11. Hutson JM, Beasley SW. Embryological controversies in testicular descent. Semin Urol. 1988;6(2):68-73.

12. Parker RM, Robison JR. Anatomy and diagnosis of torsion of the testicle. J Urol. 1971;106(2):243-7.

13. Scorer CG, Farrington GH. Congenital deformities of the testis and epididymis. London: Butterworths \& Co; 1971. p. 136-46.

14. Dickinson SJ. Structural abnormalities in the undescended testis. J Pediatr Surg. 1973;8(4):523-7.

\section{Submit your next manuscript to BioMed Central and take full advantage of:}

- Convenient online submission

- Thorough peer review

- No space constraints or color figure charges

- Immediate publication on acceptance

- Inclusion in PubMed, CAS, Scopus and Google Scholar

- Research which is freely available for redistribution 